\title{
Employability and work ability: returning to the labour market after long-term absence.
}

\author{
Staffan Nilsson and Kerstin Ekberg
}

\section{Linköping University Post Print}

\section{Tweet}

N.B.: When citing this work, cite the original article.

Original Publication:

Staffan Nilsson and Kerstin Ekberg, Employability and work ability: returning to the labour market after long-term absence, 2013, Work: A journal of Prevention, Assesment and rehabilitation, (44), 4, 449-457.

http://dx.doi.org/10.3233/WOR-2012-1402

Copyright: IOS Press

http://www.iospress.nl/

Postprint available at: Linköping University Electronic Press

http://urn.kb.se/resolve?urn=urn:nbn:se:liu:diva-69503 


\section{Employability and work ability: Returning to the labour market after long-term absence}

Staffan Nilsson ${ }^{\mathrm{a}, \mathrm{b}}$, Kerstin Ekberg ${ }^{\mathrm{a}, \mathrm{c}}$

${ }^{a}$ HELIX VINN Excellence Centre, Linköping University, 58183 Linköping, Sweden.

${ }^{\mathrm{b}}$ Centre for Policy Studies in Higher Education and Training, Department of Educational Studies, University of British Columbia, Faculty of Education, 2125 Main Mall, Vancouver, B.C., V6T 1Z4, Canada.

${ }^{c}$ National Centre for Work and Rehabilitation, Department of Medical and Health Sciences, Linköping University, 58183 Linköping, Sweden.

Corresponding author:

Staffan Nilsson, Ph.D., MPH

Centre for Policy Studies in Higher Education and Training (CHET)

Department of Educational Studies (EDST)

University of British Columbia

Faculty of Education

2125 Main Mall

Vancouver, B.C., V6T 1Z4

Canada

Tel., work: +1 604822 2593, Tel. cell.: +1 6043662508

E-mail: Staffan.Nilsson@liu.se 


\title{
Employability and work ability: Returning to the labour market after long-term absence
}

\begin{abstract}
Objective: The aim of this study was to analyse how people who return to the labour market after long-term sickness absenteeism and subsequent job loss differ in employability, work ability, health, educational level, age, and gender, compared to those who do not.

Participants: The cohort consisted of 191 individuals, 20 men and 171 women, whose employment was terminated because they had not been able to return to their regular work after taking a long-term sick leave and rehabilitation measures.

Methods: This study is based on a postal questionnaire sent out to a cohort of previous employees in a Swedish municipality in 2008.

Results: At the time of the survey, 39\% of the respondents had returned to the labour market and the remaining $61 \%$ had not. Return to the labour market after a long-term sick leave was positively associated with male gender, young age, and work ability, i.e. the ability to work with respect to health and work-related demands. Employability, educational level, and health were not significantly associated with a return to the labour market.

Conclusions: In the discourse on employability, work ability is often neglected even though it is a central aspect of an individual's ability to obtain new employment.

Key words: Unemployment, health, long-term sick leave, Sweden
\end{abstract}

\section{Introduction}

Work conditions are undergoing significant changes due to processes that have been initiated to increase effectiveness as well as cutbacks and the introduction of new ways to organise work. The conditions in working life are now characterised by increased intensity, competition, a faster pace, shorter lead times, the expansion of different kinds of contract and part-time work, the rapid emergence and the development of new knowledge and technologies, and the increasing decentralisation of responsibility [1,2,3]. These changes have led to new, rapidly changing conditions and demands for employees, among other things, to demonstrate lifelong learning, continuous development of competence, interpersonal skills, flexibility, and adaptability $[4,5,6]$. Overall, psychological and social demands [7], as well as the differences between different groups in society, have increased [8]. Employees now have an increased responsibility for risk management as well as for developing and managing their individual employability for remaining competitive on the labour market [3].

Several studies $[9,10]$ have shown positive effects of mobility (i.e. readiness to move) from jobs that are not suited to an individual's competence. However, leaving secure employment to search for a new job can be tough, and it's a difficult step for many employees to take. Reduced health can also lead to feelings of inadequacy and the belief that the employee is not competitive in the labour market, which may impede individual mobility. Nonetheless, the understanding of the relationship between health and mobility between different jobs is poor. There are indications that the prospect of gaining new employment is limited for individuals attempting to return to the labour market after long-term sick leave or unemployment [11,12]. Only 7\% of employers in Sweden would consider employing individuals that were sick-listed, and $13 \%$ were open to 
employing long-term absentees [13]. Thus, a history of sick leave as well as poor health and a reduced work ability are central aspects that affect an individual's employability after long-term illness. Work ability is in this study defined as the individual's self-rated ability to work with respect to demands at work on physical, psychological, and social health. Knowledge, skills, and attitudes are here related to the concept employability. Work ability and health are often overlooked aspects, or considered to be explicit prerequisite for, individual employability, but these parameters are rarely included in research on employability and mobility in the labour market. The relationship between work ability and employability has rarely been empirically explored.

Employability has been studied from a macro, an organisational, and an individual perspective with different target groups, with the aim of identifying potential employability factors among the unemployed, and studies have also included individuals that are currently employed $[14,15]$. From an organisational perspective, the meaning has changed from mainly referring to an individual's health and age to focusing on how individual competence, knowledge, skills, and attitudes are matching employer demands. Employability is, to a considerable extent, associated with different aspects of competence for the employed as well as the unemployed [16]. With the changes occurring in working life, the demands on individual competence are also changing accordingly.

Employability is not an assurance of actual employment, but it may increase the chances of becoming employed. Employability is commonly considered to incorporate factors related to an individual's preparation for work, the ability to get a job with security, and the ability to successfully manage and keep the job, but factors related to career advancement, such as the individual's capability to move from unemployment to a job or from one job to another, are also incorporated into employability [17,2]. Employability is not only related to individual ability or the formalised competence and credentials gained through educational institutions and other organised educational activities [3,15]. It is a multidimensional and complex concept that can be related to, among other things, general transferable competence, continuous learning, and competence development [18]. In a broader definition, the concept also includes dimensions such as personal characteristics and talents, informal contacts, personal social networks, age, gender, health, work ability, and other factors that are not easily gained through formal education. However, in this study, employability will be defined more conservatively. Work ability, health, educational level, age, and gender will be treated as separate variables that are not included in the employability concept. This will enable a more specific in-depth analysis of the relationship between the most central variables relevant to the return to the labour market after long-term absence $[11,12,19,20]$.

Delfillippi and Arthur have described three dimensions of employability: know-why, knowhow, and know-whom [21]. These dimensions can also be compared to the aspects of employability presented by Fugate et al. [22], which are adaptability, career identity (comparable to know-why), social capital (comparable to know-whom), and human capital (comparable to know-how). Social capital, or know-whom, is associated with formal and informal career-related networks, which can be the basis for social support when an individual is facing negative experiences such as sickness or unemployment. Career identity, career competencies, or knowwhy, is related to motivation, individual values, and finding personal meaning. This aspect of employability can also be related to self-efficacy or self-esteem [23]. Human capital, or knowhow, is professional career-related competence acquired through educational activities and continuous learning in the workplace. Education is often considered one of the most central employability aspects. In this study, employability refers to the individual's ability to find a job, 
competence, experience, educational level (human capital), social contacts and networks, knowledge of the labour market (social capital), personal characteristics, propensity for mobility, self-efficacy, self-esteem, and confidence in individual employability assets as motivational factors (know-why).

The aim of this study was to develop knowledge about what factors predict return to the labour market for individuals who have had their employment terminated after a long-term sick leave. Employability, work ability, and educational level of these individuals were investigated. Thus, one specific research question was addressed: how do people who return to the labour market after long term absenteeism and job loss differ in employability, work ability, health, educational level, age, and gender, compared to those who do not?

\section{Methods}

\subsection{The sample}

A postal questionnaire was sent out in 2008 to a cohort of previously employed individuals in a Swedish municipality. Their employment had been terminated during 2005-2007 after a longterm sick leave, and rehabilitation measures did not allow for these individuals to return to their regular work. All of the individuals in the cohort had been offered severance payment and a return-to work program, which was an adjustment program aimed at supporting their attempts to return to the labour market. The cohort contained a total of 191 people, 20 (10\%) men and 171 $(90 \%)$ women. The average age of the individuals was 50 years. The questionnaire was followed by two reminders, and a total of 109 (57\%) individuals answered the survey.

Through administrative records, background information was available for all of the people in the cohort. Analyses of the non-respondents showed that the sample was statistically representative of the cohort with regard to most of the available variables, including age, gender, occupational group, and diagnoses that caused the long-term absence from work. The most common diagnoses were psychological disorders (43\%) and musculoskeletal disorders (42\%). This is also consistent with results from a previous study in Sweden where these two groups of diagnosis were predominant [24]. Also, a combination of these diagnoses was not uncommon. Of the non-respondents, $86 \%$ were women, $14 \%$ were men, and their average age was 48 years.

\subsection{Materials}

The questionnaire included questions concerning perceived work ability $[25,26]$ and perceptions of employability in the labour market [27,28]. The questionnaire also included validated questions on background variables, symptoms, working conditions, health, and quality of life (EQ-5D) [29,30].

Additionally, the questionnaire contained questions about the respondents' perceptions of their professional competence in relation to their previous job, including the respondents' retrospective view of their attitude towards and views on the opportunities of finding new employment and the possible impact of different measures on the possibility of avoiding long-term absence.

The questionnaire mainly consisted of attitude questions or statements on 5- and 7-point Likert-type scales [31] with response alternatives ranging from strongly disagree (1) to a neutral alternative ( 3 or 5 ) to strongly agree (5 or 7). For instance, statements related to employability included: "My competence is sought after on the labour market", "I could easily find new (equivalent or better) job in another organisation", and "I have a social network that I can use to 
get a new (equivalent or better) job“ (translated from Swedish). Some questions had fixed response alternatives on a nominal scale, e.g. gender. Also, the respondents were asked about their formal educational level: "What is the highest educational level you have obtained?" The response alternatives were: higher education, secondary education, and compulsory education.

For most questions, a higher score indicated a higher presence of the construct. For some questions, the scale was turned around, and these scales were inverted before the data were analysed.

\subsection{Measures}

\subsubsection{Health}

Generic health was measured using the validated standardised instrument EuroQol (EQ-5D), which consisted of two parts [29,30]. The first part consisted of 5 dimensions that described health in terms of mobility, self-care, usual activities, pain or discomfort, and anxiety or depression. The instrument yielded a total of 243 possible health states with 1.0 indicating full health. The second part of EuroQol included the EQ visual analogue scale (EQ-VAS) with end points of zero for the worst imaginable health state and 100 for the best imaginable health state.

\subsubsection{Work ability}

Work ability is defined as the individual's self-rated ability to work with respect to health and demands of the job. The validated Work Ability Index (WAI) was used to evaluate the patients' self-rated work ability [32]. This instrument included 7 items concerning current work ability compared to lifetime best work ability in terms of the demands of the job, the number of current diseases diagnosed by a physician, estimated work impairments because of disease, sick leave during the past year, psychological resources, and personal prognosis of work ability [33].

\subsubsection{Employability}

Individual employability was measured through a new construct that consisted of questions that were focused on different aspects of employability. The respondents rated how important they perceived different employability aspects for acquiring a new job related to know-how, knowwhom, and know-why [21,22,23]. The employability construct included questions related to know-how that were measured by two questions on how the respondents rated their competence and experience as well as how they perceived their competence and previous experience in the labour market. The aspect of employability referred to as know-whom was measured by two questions on the respondent's view of access to social networks that could be used to acquire a new (equivalent or better) job as well as their knowledge of other organisations in which they could find new employment (equivalent or better). Employability also contained an aspect of career-related self-esteem and self-efficacy. This aspect was measured through three questions concerning the extent to which the respondents viewed their personal characteristics as an asset for acquiring a new equivalent or better job in another organisation or firm (career self-esteem), how individuals generally rated their chances of finding new employment (career self-efficacy), and the respondents' propensity for mobility. All variables concerning self-rated individual employability were included in the same factor in a principal component analysis. Thus, only one component was extracted, which reduced the seven items to one component. All items in the selfrated employability construct were significantly correlated (the correlations ranged from 0.3 to $0.9, \mathrm{p}<0.05)$, and the reliability of the employability construct had a Cronbach's value of $\alpha=0.90$. 


\subsection{Statistical analysis}

Differences in point estimates of the mean were measured for statistical significance through ttests as well as analyses of variance (ANOVA) and Bonferroni post-hoc tests. For data on an ordinal scale, Mann-Whiney U tests were calculated. For nominal data, the statistical significance of the differences in frequency distribution was measured through $\chi^{2}$ tests [34]. Pearson's $\left(r_{p}\right)$ and Spearman's $\left(r_{s}\right)$ correlation coefficients were calculated for data on the interval and ordinal scales, respectively. A bivariate logistic regression model was used to show how work ability, health, employability, as well as the demographic variables, age and education, could predict dichotomised variable employment status. The alpha level was consistently set at 0.05 , and SPSS software (17.0) was used for all statistical analyses.

Factor analyses (principal component analyses) were used to reduce the number of variables in sections of the questionnaire that pertained to what general qualifications are perceived to be important when searching for new employment as well as the variables related to self-rated individual employability. The internal consistency of all new constructs was measured by Cronbach's $\alpha$ value. The factors were calculated as means based on an individual level of the variables associated with the respective factor.

\section{Results}

\subsection{Demographics}

This study was based on 109 individuals, including 100 (92\%) women and 9 (8\%) men. The educational level varied in the sample population: $31 \%$ had studied at a higher education institution, e.g. university, $44 \%$ had a degree from a secondary education program and $24 \%$ had attended only 9-year compulsory school.

At the time of the survey, $39 \%$ of the respondents had returned to the labour market and the remaining $61 \%$ were relying on other forms of financial support, such as sickness or unemployment benefits. Of those who were employed, $44 \%$ were working full time and the rest (56\%) were working part time ( $85 \%$ the part-time employees were working half time or more).

\subsection{Health}

The respondents estimated their health as 6.22 (95\% CI: 5.76-6.68) on a 10-point scale. Those who had returned to the labour market estimated their health to be significantly better ( $\bar{x}=6.81$, $\mathrm{sd}=2.24)$ than those who had not returned $(\square=5.84, \mathrm{sd}=2.36)(\mathrm{t}(102)=2.11, \mathrm{p}=0.038)$. There were no statistically significant differences in self-rated health $(\mathrm{F}(2,98)=2.51, \mathrm{p}=0.087)$ that could be attributed to educational level.

\subsection{Work ability}

The work ability of the cohort was estimated to be 5.15 (95\% CI: 4.50-5.80) on a scale from one to ten. The respondents who had returned to the labour market estimated their work ability was significantly better $(\square=7.26$, sd=2.33) than those who were not working ( $\square=3.77$, sd=3.26) $(\mathrm{t}(103)=6.44, \mathrm{p}<0.001)$. There were no statistically significant differences in self-rated work ability $(\mathrm{F}(2,100)=0.51, \mathrm{p}=0.60)$ that could be attributed to educational level. 


\subsection{Employability}

The respondents estimated their employability to be 2.22 (95\% CI: 2.00-2.45) on a 5-point scale. Of the self-rated individual employability aspects, or the estimation of the individual opportunities for finding a new employment, the highest score was given to variables related to self-efficacy. The highest scores were given to individual competence and the experience of being sought after in the labour market, which were perceived as assets in the search for new work. These variables were rated slightly higher than confidence among personal characteristics that could be an asset for finding a new job in another firm or organisation. Individual competence and the experience of being sought after were rated significantly higher than access to a social network or contacts along with knowledge of other firms or organisations in which they could find employment. The propensity for mobility or readiness to move in order to find a new (equivalent or better) job was rated significantly lower than all other individual employability aspects (Table 1).

\section{TABLE 1}

Self-rated employability was not associated with age $\left(r_{p}=-0.044 ; p=0.67\right)$. Employability was significantly, but not strongly, related to self-rated health $\left(\mathrm{r}_{\mathrm{p}}=0.36 ; \mathrm{p}<0.001\right)$ and work ability $\left(\mathrm{r}_{\mathrm{p}}=0.26 ; \mathrm{p}=0.010\right)$ (Table 2).

\section{TABLE 2}

There was a statistically significant relationship between self-rated individual employability and the highest level of education. The respondents who had a university education $(\bar{x}=2.90$, $\mathrm{sd}=1.24)$ regarded their employability as significantly better than those with secondary education $(\bar{X}=2.00, \mathrm{sd}=0.84)$ or compulsory schooling $(\bar{X}=1.80, \mathrm{sd}=1.01)(\mathrm{F}(2,92)=9.43, \mathrm{p}<0.001)$. T-tests showed that the university-educated individuals rated all items on the employability construct significantly higher than those with secondary or compulsory schooling, except for readiness to move. However, education was not a decisive factor for individuals who actually returned to the labour market $\left(\chi^{2}(1)=0.28, p=0.59\right)$. Approximately, $42 \%$ of university-educated individuals returned to the labour market, compared to $37 \%$ of individuals with secondary education or compulsory schooling.

\subsection{Return to the labour market}

Of the 42 individuals who returned to employment at the time of the survey, 34 were women and 8 were men, which indicated that $90 \%$ of the men in the sample found new jobs, compared to only $34 \%$ of the women $\left(\chi^{2}(1)=10.50, p=0.0012\right)$. However, it should be noted that the number of men in this sample was small. The individuals who had found new employment were significantly younger $(\bar{X}=47.10$ years, $\mathrm{sd}=8.52)$ than those who had not $(\bar{X}=51.48$ years, $\mathrm{sd}=8.91)(\mathrm{t}(106)=2.52, \mathrm{p}=0.013)$. There were no statistically significant differences between those who had found new employment and those who had not returned to the labour market, regarding their educational level $\left(\chi^{2}(3)=2.21, \mathrm{p}=0.53\right)$ or their income from previous employment $(\mathrm{t}(92)=0.28, \mathrm{p}=0.78)$.

Those who had returned to the labour market considered themselves to have a social network that they could use to get a new (equivalent or better) job $(\mathrm{t}(71)=2.18, \mathrm{p}=0.033)$ as well as better knowledge of other firms/organisations in which they could get a job $(\mathrm{t}(63)=3.17, \mathrm{p}=0.0020)$, 
compared to individuals who had not returned to the labour market. Furthermore, individuals who found new work also believe their personal characteristics made it easier for them to get a new (equivalent or better) job in another firm or organisation $(\mathrm{t}(95)=2.51, \mathrm{p}=0.010)$. There were no significant differences between those with a job and unemployed individuals regarding any of the other variables pertaining to individual employability. In other words, there was no difference in their beliefs in their abilities or that they would have little trouble in finding a new equivalent job in another firm $(\mathrm{t}(96)=0.59, \mathrm{p}=0.55)$, beliefs in their competence $(\mathrm{t}(96)=0.18, \mathrm{p}=0.85)$, or beliefs that their experience $(\mathrm{t}(95)=0.062, \mathrm{p}=0.95)$ is sought after in the labour market and their propensity for mobility $(\mathrm{t}(66)=1.83, \mathrm{p}=0.071)$.

Thus, there were significant differences between those who found a new job and those who did not in employability aspects related to social capital, or know-whom, and personal characteristics, which are associated with career self-efficacy. However, there were no significant differences in employment status associated with competence, experience, and educational level (in other words, human capital, or know-how).

Those who had found new employment thought to a greater extent that they could have performed more qualified tasks during their previous employment. Thus, a higher proportion of those who returned to the labour market considered themselves to be over-skilled for their previous job compared to those who were unemployed. There was no statistically significant difference in the proportion that thought they were under-qualified or lacked the competence required to perform the previous job successfully $\left(\chi^{2}(2)=1.18, p=0.0031\right)$. Furthermore, those who were employed considered themselves to have the occupational knowledge required for the occupations they were interested in to a higher degree than those who were not working $(\mathrm{t}(93)=1.99, \mathrm{p}=0.049)$.

Bivariate logistic regression model analyses were performed in order to demonstrate the predictive value of work ability, health, employability, age, and education, on employment status (Table 3).

\section{TABLE 3}

In Model 1, odds ratios (OR) for work ability, health, and employability are presented. In Model 2, OR for work ability, health, employability (Step 1), age and education (Step 2) are presented. The regression analyses showed that only work ability was significantly associated with returning to the labour market.

\section{Discussion}

The return to the labour market after a long-term sick leave was positively associated to young age, male gender, and work ability in the present study. These findings are also supported in previous research $[11,19,20]$. The aggregated employability construct, which consisted of aspects associated with know-how, know-why, and know-whom, as well as formal education, had little predictive value for return to the labour market after long-term sick leave and subsequent job loss in this sample population. However, some specific aspects of employability, such as social capital, know-whom, and personal characteristics, were significantly related to returning to the labour market, while human capital was not. Having a social network of contacts and knowledge of organisations where it would be possible to find new work were positively associated with the return to the labour market when analysed separately. Social networks that provide social support 
have also been shown to be central for handling stressful events such as sickness absence and unemployment in a previous study [35].

Furthermore, returning to the labour market was positively associated with confidence in personal resources, the belief that personal characteristics or personality are a resource when applying for a job, greater career self-efficacy, and self-esteem. This finding was also supported by findings in previous research [36,37]. A previous study has shown that low self-efficacy may be a result of the sickness absence rather than a precursor of it [19].

Another thing that separated those who had returned to the labour market from those who had not was that the employed individuals believed they could have performed more qualified tasks during their previous job. Thus, those who had found new employment considered themselves to be over-skilled for their previous job to a greater extent than those who had not found employment. This may indicate that the respondents who had found new employment had more self-esteem, were more competent and better qualified in general, or that one of the reasons for their sickness absence was lack of correspondence between their competence and previous job demands.

Individual conditions, including health and work ability, were central to how employable or employment-worthy an individual perceived themselves to be. Moreover, self-rated employability was positively associated with educational level. This observation was consistent with the results in a previous study [38]. However, contrary to several previous studies [20,36], among the respondents, employability and educational level were not associated with returning to the labour market. This result may imply that measures or programs initiated to facilitate an individual's return to the labour market after long-term sick leave should focus more on rehabilitation, increasing an individual's work ability, and strengthening their coupling to the labour market through, for example, job training [39] as well their social networks, rather than enhancing measures focused on formal education and human capital. However, this suggestion implies considerable change in current practices and needs to be verified and substantiated by additional research. Demands for increased levels of self-initiative and individual agency, which typically increase individual employability [2,3], did not appear to affect the chances of finding a new job for individuals returning to the labour market after a long-term absence.

Employability and work ability are not static concepts. Technological innovation and the development of new knowledge lead to new and ever-changing demands in the labour market. The skills that are required to manage a specific job and to be employable are changing continuously. Everyone is expected to develop and manage his or her individual employability. To do this, an individual is expected to continuously learn and develop his or her personal and professional competence [2,3]. However, when employability is discussed, health and work ability are seldom included in the discussion, even though they are central aspects of an individual's ability to obtain new employment.

Generally, the chances of finding new employment after long-term sick leave are very limited. Even if an individual is employable in formal aspects, he or she may not be considered worthy of employment. Selection mechanisms used to determine who becomes employed may be tougher and have more severe consequences for individuals who have been unemployed and/or sick for a long period of time $[9,11,13,20,39]$.

A gap in the curriculum vitae (CV) from being on long-term sick leave and/or unemployment may have more severe consequences for the well-educated than for those with less education. Educational levels were associated with the kinds of jobs that individuals sought and applied for. Jobs requiring higher education may be associated to a greater extent with demands at work that require an individual to be updated on specific skills and competence. Additionally, for jobs 
requiring higher education, an absence from the labour market can affect how well the individual is expected to perform. For jobs requiring little or no education, an absence from the labour market may have smaller consequences on the individual's expected productivity. Education may, in a sense, be considered to be a perishable product by employers with a diminishing value over time.

It should be noted that the respondents in the present study had their employment terminated after long-term sick absence in one Swedish municipality. The characteristics of the subjects may not be representative of persons in other regions. How far the present results may apply in other contexts is uncertain.

The respondents in the study estimated their health as 6.22 on a 10-point scale. In comparison, in a previous study women employed in service and care occupations in Sweden estimated their health as 8.4, and unemployed women estimated their health as 7.6 on the same scale [40]. Thus, the self-estimated health of the cohort in this study was poorer than some other comparable groups. Furthermore, the respondents rated their work ability as 5.15. The work ability of the cohort was estimated as slightly higher than in other comparable groups. For example, a group $(n=138)$ on sick leave due to musculoskeletal problems and/or stress-related illness presented in a previous study, rated their work ability (during their sick absence) as 2.9 on the same scale [41].

There are some other limitations of the present study. For instance, there are possible contributing variables that were not included in the analyses that may have influenced the results. We have chosen to control for age and gender. However, there are other possible confounders of the work or variables relevant to the return the labour market after long-term absence that were not measured or controlled for in this study. In previous research other factors have been associated to return to the labour market, including job demands, control over work, social support, motivation, previous illness or injuries, types of rehabilitation measures, and number of years of prior work experience, and ethnicity [12,20,36].

\section{Conclusions}

In the present study, some employability aspects that were associated with know-whom and know-why appeared to facilitate a return to the labour market after a long-term sickness absence. Know-how, human capital, and education (as well as training, work experience, knowledge, and skills) had no explanatory value. The lack of correlation between overall employability and a return to the labour market implies that a more traditional view of employability may be less relevant to groups re-entering the labour market after a long-term absence due to sickness. In this case, the most important predictor of returning to the labour market was self-rated individual work ability. Employability may be associated with career building and be of greater importance to those who are more strongly established in the labour market. As such, it appears that employability (consisting of know-how, know-why, and know-whom) and work ability are separate constructs, which indicates that the meaning and the content of the employability concept are likely to vary in different contexts. For individuals returning to the labour market after long-term sick leave, work ability is a more relevant central concept than other aspects of employability and education.

In research on mobility and returning to the labour market after sick leave, it is important to consider different aspects of employability. When a broader approach to, and widened definition of, the employability concept is used, it is important to include and separate aspects such as health and work ability in analyses. 


\section{References}

[1] Brown P, Hesketh A, Williams S. Employability in a knowledge-driven economy. Journal of Education and Work. 2003; 16(2): 107-126.

[2] Knight PT, Yorke M. Learning, Curriculum and Employability in Higher Education. London: Routledge; 2004.

[3] Nilsson S. Enhancing Individual Employability - The perspective of engineering graduates. Education \& Training. 2010; 52(6/7): 540-551.

[4] Ekberg K, Eklund J, Ellström PE, Johansson S. Tid för utveckling? [in Swedish] [Time for development]. Lund, Sweden: Studentlitteratur; 2006.

[5] Ekberg K. Workplace health-influences and interventions. In: Nilsen P, editor. Strategies for health: an anthology. Linköping: Linköping University, Department of Health and Society; 2007. p. 46-58.

[6] Felstead A, Fuller A, Jewson N, Kakavelakis K, Unwin L. Grooving to the same tunes? Learning, training and productive systems in the aerobics studio. Work, Employment \& Society. 2007; 21(2): 189-208.

[7] Marklund S. Arbetsliv och hälsa 2000. [in Swedish] [Worklife and health in Sweden 2000]. Stockholm: Arbetslivsinstitutet och Arbetarskyddsstyrelsen; 2000.

[8] Härenstam A, Marklund S, Berntson E, Bolin M, Ylander J. Understanding the organisational impact on working conditions and health. Stockholm: The Swedish National Institute of Working Life; 2006.

[9] Ahlgren $\AA$, Bergroth A, Ekholm J. Work resumption or not after rehabilitation? A descriptive study from six social insurance offices. International Journal of Rehabilitation Research. 2004; 27(3): 171-180.

[10] Kivimäki M, Vahtera J, Elovainio MJ, Virtanen M. Human Costs of Organizational downsizing: Comparing health trends between leavers and stayers. American Journal of Community Psychology. 2003; 32: 57-67.

[11] Ahlgren Å, Bergroth A, Ekholm J, Schüldt K. Work resumption after vocational rehabilitation: a follow-up two years after completed rehabilitation. Work. 2003; 28: 343-354.

[12] Labriola K. Conceptual framework of sickness absence and return to work, focusing on both the individual and the contextual level. Work. 2008; 30: 377-387.

[13] Mörtvik R, Rautio K. Jakten på superarbetskraften fortsätter! [in Swedish] [The hunt for the super-workforce continues!]. Stockholm: The Swedish Confederation for Professional Employees (TCO); 2008.

[14] Gazier B. Employability: concepts and policies. Berlin: European Employment Observatory; 1999.

[15] McQuaid RW, Lindsay C. The Concept of Employability. Urban Studies. 2005; 42(2): 197-219.

[16] Garsten C, Jacobsson K. Learning to be employable: new agendas on work, responsibility and learning in a globalizing world. New York: Palgrave Macmillan; 2004.

[17] Hillage J, Pollard E. Employability: Developing a framework for policy analysis. London: Department for Education and Employment; 1998.

[18] Harvey L. Defining and measuring employability. Quality in Higher Education. 2001; 7(2): 97-109. 
[19] Labriola M, Lund T, Christensen KB, Albertsen K, Bültmann U, Jensen JN, Villandsen E. Does self-efficacy predict return-to-work after sickness absence? A prospective study among 930 employees with sickness absence for three weeks or more. Work. 2007; 29: 233-238.

[20] Marnetoft SU, Selander J, Bergrot A, Ekholm J. Factors associated with successful vocational rehabilitation in a Swedish rural area. Journal of Rehabilitation Medicine. 2001; (33): 71-78.

[21] Defillippi RJ, Arthur MB. The boundaryless career: a competency-based perspective. Journal of Organizational Behavior. 1994; 15(4): 307-324.

[22] Fugate M, Kinicki AJ, Ashforth BE. Employability: a psycho-social construct, its dimensions, and implications. Journal of Vocational Behaviour. 2004; 65: 14-38.

[23] McArdle S, Waters L, Briscoe JP, Hall DT. Employability during unemployment: adaptability, career identity and human and social capital. Journal of Vocational Behavior. 2007; 71(2): 247-264.

[24] Aronsson G, Dallner M, Gustafsson K. Yrkes- och arbetsplatsinlåsning: en empirisk studie av omfattning och hälsokonsekvenser [in Swedish] [Locked-in, in the occupation and the working place: an empirical study of prevalence and health consequencies]. Arbete och Hälsa. 2002; 5: 1-25.

[25] Tuomi K, Huuhtanen P, Nykyri E, Ilmarinen J. Promotion of work ability, the quality of work and retirement. Occupational Medicine. 2001; 51: 318-324.

[26] Tuomi K, Ilmarinen J, Jahkola A, Katajarime L, Tulkki A. Work ability index. Helsinki: Institute of Occupational health; 1994.

[27] Berntson E, Sverke M, Marklund S. Predicting perceived employability: human capital or labour market opportunities? Economic and Industrial Democracy. 2006; 27(2): 223244.

[28] van der Heijde CM, van der Heijden BIJM. A competence-based and multidimensional operationalization and measurement of employability. Human Resource Management. 2006; 45(3): 449-476.

[29] Rabin R, de Charro F. EQ-5D: a measure of health status from the EuroQol Group. Annals of Medicine. 2001; 33(5): 337-343.

[30] The EuroQol Group. EuroQol-A new facility for the measurement of health related quality of life. Health Policy. 1990; 16: 199-208.

[31] Likert R. A. Technique for the Measurement of Attitudes. Archives of Psychology. 1932; 140: 1-55.

[32] Tuomi K, Ilmarinen J, Jahkola A, Katajarinne L, Tulkki A. Work ability index. 2nd revised ed. Helsinki: Finnish Institute of Occupational Health; 1998.

[33] Ilmarinen JE. Aging workers. Occupational and Environmental Medicine. 2001; 58(8): 546-552.

[34] Hinkle DE, Wiersma W, Jurs SG. Applied Statistics for the Behavioral Sciences. Boston: Houghton Mifflin Company; 2003.

[35] McKee-Ryan FM, Song Z, Wanberg CR, Kinicki AJ. Psychological and physical wellbeing during unemployment: a meta-analytic study. Journal of Applied Psychology. 2005; 90(1): 53-76.

[36] Melin R, Fugl-Meyer A. On prediction of vocational rehabilitation outcome at a Swedish employability institute. Journal of Rehabilitation Medicine. 2003; 35: 284-289.

[37] Regenold M, Sherman MF, Fenzel M. Getting back to work: self-efficacy as a predictor of employment outcome. Psychiatric Rehabilitation Journal. 1999; 22(4); 361-367. 
[38] Berntson E. Employability perceptions: nature, determinants, and implications for health and well-being (dissertation). Stockholm: Department of Psychology, Stockholm University; 2008.

[39] Marnetoft SU, Selander J. Multidisciplinary vocational rehabilitation focusing on work training and case management for unemployed sick-listed people. International Journal of Rehabilitation Research. 2000; 23: 271-279.

[40] Eriksson E, Nordlund A. Health and health related quality of life as measured by the EQ-5D and the SF-36 in south east Sweden: results from two population surveys. Linköping: Folkhälsovetenskapligt Centrum, Linköping University; 2002.

[41] Norgren C, Ekberg K, Öberg B. Health and functioning of employees with muscelosceletal or mental stress disorders - analysis of subgroups based on ICD-10 and work ability. Boston: Sixth International Scientific Conference on Prevention of WorkRelated Muscelosceletal Disorders; 2007. 
Table 1: Means $(\bar{X})$ and $95 \%$ confidence intervals (CI) for general perceptions of employability-based occupational status. Estimations were made on a 5-point scale.

\begin{tabular}{|c|c|c|c|c|c|c|c|c|c|}
\hline & \multicolumn{3}{|c|}{ Total } & \multicolumn{3}{|c|}{ Working } & \multicolumn{3}{|c|}{ Not working } \\
\hline & $\mathrm{n}$ & $\bar{X}$ & $95 \% \mathrm{CI}$ & $\mathrm{n}$ & $\bar{X}$ & $95 \% \mathrm{CI}$ & $\mathrm{n}$ & $\bar{X}$ & $95 \% \mathrm{CI}$ \\
\hline Competence & 98 & 2.82 & $2.51-3.12$ & 40 & 2.85 & $2.35-3.35$ & 58 & 2.79 & $2.41-3.18$ \\
\hline Experience & 97 & 2.71 & $2.41-3.01$ & 40 & 2.70 & $2.21-3.19$ & 57 & 2.72 & $2.33-3.11$ \\
\hline $\begin{array}{l}\text { Personal } \\
\text { characteristics }\end{array}$ & 97 & 2.34 & $2.06-2.62$ & 40 & 2.75 & $2.30-3.20$ & 57 & 2.05 & $1.71-2.40$ \\
\hline $\begin{array}{l}\text { Ability to find a } \\
\text { new job }\end{array}$ & 98 & 2.27 & $1.96-2.57$ & 40 & 2.38 & $1.86-2.89$ & 58 & 2.19 & $1.80-2.58$ \\
\hline Social network & 97 & 2.02 & $1.74-2.30$ & 40 & 2.40 & $1.90-2.90$ & 57 & 1.75 & $1.43-2.08$ \\
\hline $\begin{array}{l}\text { Knowledge of } \\
\text { other firms }\end{array}$ & 97 & 2.00 & $1.73-2.27$ & 40 & 2.53 & $2.03-3.02$ & 57 & 1.63 & $1.35-1.91$ \\
\hline Mobility & 97 & 1.47 & $1.26-1.69$ & 40 & 1.73 & $1.32-2.13$ & 57 & 1.30 & $1.06-1.54$ \\
\hline Employability* & 98 & 2.22 & $2.00-2.45$ & 40 & 2.48 & $2.09-2.86$ & 58 & 2.05 & $1.79-2.32$ \\
\hline
\end{tabular}


Table 2: Spearman's correlation coefficients between work ability, health, employability, education, and age.

\begin{tabular}{lllllll}
\hline & $\bar{X}$ & Work ability & Health & Employability & Education & Age \\
\hline Work ability & 5.15 & 1 & & & & \\
Health & 6.22 & $0.67^{*}$ & 1 & & & \\
Employability & 2.22 & $0.26^{*}$ & $0.36^{*}$ & 1 & & \\
Education & 2.07 & 0.10 & $0.22^{*}$ & $0.38^{*}$ & 1 & \\
Age & 49.81 & $0.26^{*}$ & 0.032 & 0.044 & 0.060 & 1 \\
\hline
\end{tabular}

* Correlation is significant at the 0.05 level. 
Table 3: Bivariate logistic regressions predicting employment status. The results are presented as odds ratios (OR) with $95 \%$ confidence intervals (CI).

\begin{tabular}{lllll}
\hline & Model 1 & & Model 2 & \\
\hline & OR & $95 \%$ CI & OR & $95 \%$ CI \\
\hline Work ability & $1.78^{*}$ & $1.32-2.39$ & $1.76^{*}$ & $1.31-2.37$ \\
Health & 0.73 & $0.51-104$ & 0.73 & $0.51-1.051$ \\
Employability & 1.08 & $0.64-1.82$ & 1.08 & $0.61-1.90$ \\
& & & & \\
Age & & 0.99 & $0.94-1.05$ \\
Education & & & 0.99 & $0.46-2.17$ \\
& & & &
\end{tabular}

